\title{
Defects in diamonds as the basic adhesion grinding
}

\author{
Vyacheslav Popov ${ }^{1, *}$, Daniel Rychkov ${ }^{1}$, and Pavel Arkhipov ${ }^{1}$ \\ ${ }^{1}$ Bratsk State University, 665709, 40 Makarenko, Bratsk, Russian Federation
}

\begin{abstract}
Defects arising in diamond crystals during their synthesis, give rise to the formation of more complex defects that arise in the operational process of diamonds themselves. In case of external action these defects have immediate strong effect on operating characteristics of devices, products or tools containing diamonds. When external action these defects and have immediate strong effect on production characteristics of devices, products or instruments containing diamonds. This is particularly manifested in the grinding of tough, ductile materials based on aluminum, magnesium or titanium. Developed on the basis of modern digital technology and molecular dynamics visualization method allows to show it at the atomic level. The problems of practical application of the combined electric diamond grinding are examined. Experiments were conducted on the grinding tool materials with metal-bonded diamond grinding wheels.
\end{abstract}

\section{Introduction}

The basic parameter which identifies quantitative, qualitative and price characteristics of engineering projects of the time is a possibility to carry out a virtual experiment. This is less expensive but more effective and safe against a physical one. One of the key criteria of rapid prototypical industry (RP) is a possibility to visualize a model in material. Modeling by the molecular dynamics method (MD) provides an opportunity to visualize an atomic structure of the material in the model. RP models make possible to carry out some special experiments, which are not available in the realworld, while MD models provide for experiments at the atomic structure of the material being created.

Recent years have revealed a stable interest tendency of manufactures to diamond grinding wheels [1]. Hightech diamond tools, in spite of their crashproof properties, given to lose their free-cutting features during grinding because of diamond crystals wear out or their adhesion loading.

Study of the process in the contact zone, description of reasons of diamond grinding wheels (DGW) efficiency loss using a computer technique for modeling of the structure and material properties at cutting-make the study to be fundamental.

The study concluded that a loaded layer could be formed in a few stages different by nature and which were corroborated with an up-to-date scientific investigation of adhesion [2-7]. In each case in machining and grinding different materials with different abrasives, different adhesion mechanisms, which are more relevant to a specific thermodynamic, phase or kinetic process can dominate over there [8-18]. In order to expand the mechanism of adhesion, it is necessary to carry out comprehensive analyses in terms of material science, mechanical engineering technology, chemistry and solid-state physics by atomic visualization of juvenile surfaces $[19,20]$. To this effect it is necessary to take into account the specific character of artificial diamond synthesis, which was practically neglected by previous researchers.

However, it is very important to know what internal and surface defects have diamond crystals, which are used for fabrication of modern grinding tools.

At present metal-synthetic diamond crystals are used for abrasive tools. Such crystals can be formed under high pressure and temperature in the metal melt with dissolved carbon therein. This is attributed to the fact that a growth medium on the basis of metal catalyst, e.g. like nickel, chromium or cobalt is well able to dissolve graphite. All side phases in the form of inclusions can penetrate into crystals in the reaction chamber [17-21].

Thus, nearly each diamond has nanodimensional structural imperfections and defects after synthesis. All researchers, whose investigations have been dedicated to the issues of synthetic diamond, seem to be unanimous in the idea, that defects occurrence in diamonds has a significant influence on their physical properties (mechanical, magnetic, electrical, etc.), particularly on their hardnees, and specifically on their heat resistance after synthesis [22].

So far as diamond properties are defined by the defects, the operating characteristics of diamond tool, containing diamonds, depend directly on them. The tool experiences some kind of external influence (pressure, temperature, oxidation, electrical current, etc.) during its grinding and hence, the behaviour of diamond in the tool depends on this influence as well. There is evidence that modelling of cutting operation, considering main defects which are inherent in synthetic diamonds will be more accurate both from a fundamental point of view and a computer modelling of solid-state physics objects.

* Corresponding author: berkutoff@rambler.ru 


\section{Influence of point defects (microflaw)}

Nitrogen is the main inclusion of the diamond-type crystal lattice which initiates formation of lot of point defects $[19,22]$. Thus, single vacancy defects (Fig. 1, a), single substituent and interstitial atoms (Fig. 1, b, c), could be passed into multi-vacancies clusters.
So far as substituents belong to a different chemical element and of a different shape, crystal lattice can be widened or compressed under the influence of such transitions. Stored in the lattice energy, being released during grinding, might bring to formation of cracks inside diamond and dicrease its strength properties.

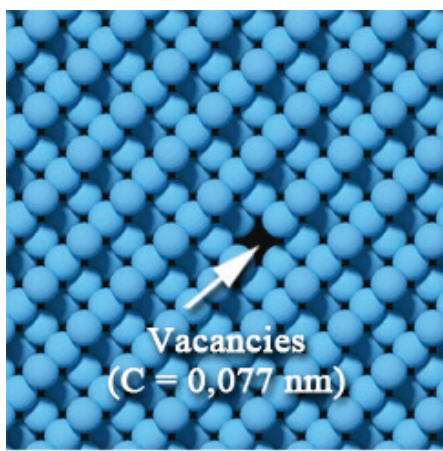

a)

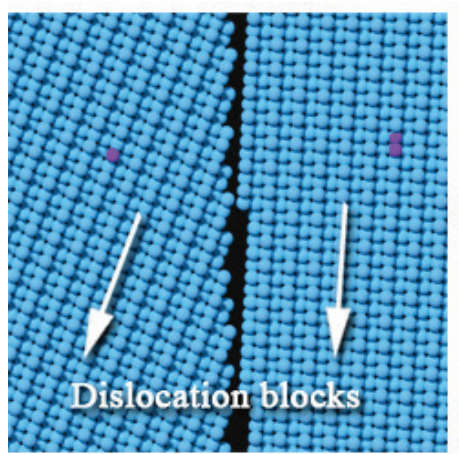

d)

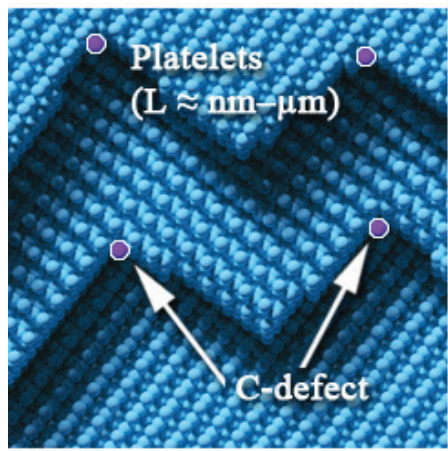

g)

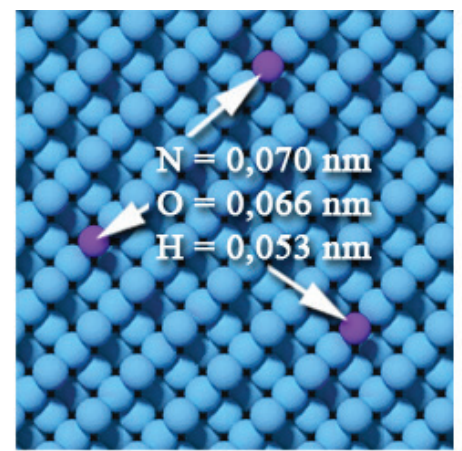

b)

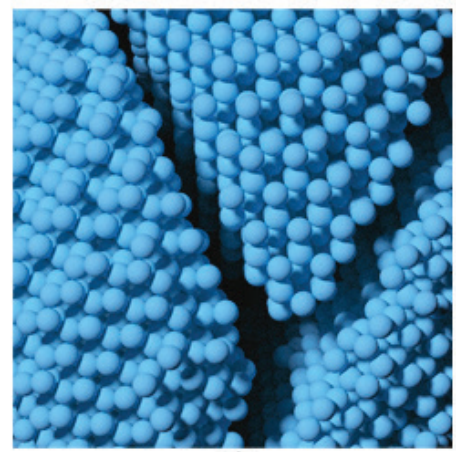

e)

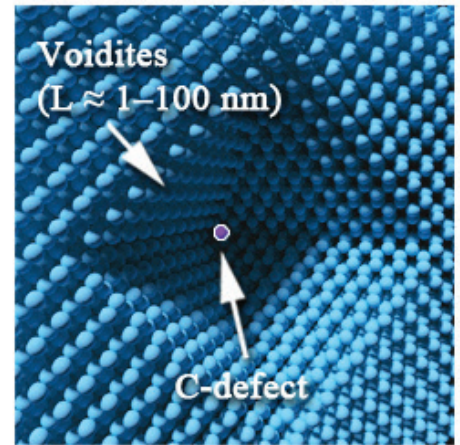

h)

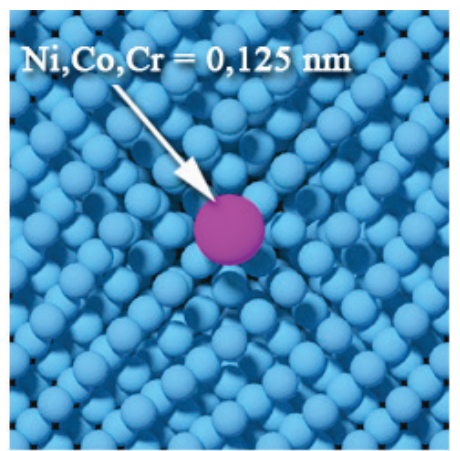

c)

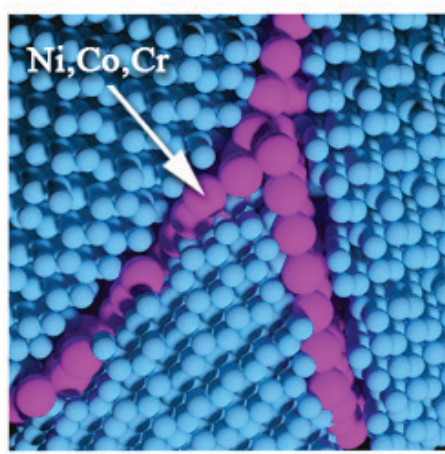

f)

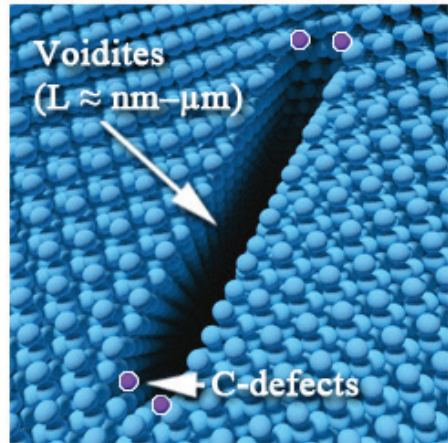

i)

Fig. 1. Modelling of synthetic diamond defects, with respect to the crystal morphology. Point defects (microflows): a) vacancies; b) substituents (C-defect); c) interstitial atoms; d) dislocations. Three-dimensional defects (macrodefects): e) interblock cracks; f) metal contamination; j) platelets defects; h) octahendra voidites; i) planar voidites.

\section{Influence of three-dimensional defects (macrodefects)}

There is evidence that adhesion of grinded off material to the grinding wheel bond, or so to say loading itself, mostly occurs due to some defects of crystal surfaces. As a rule, they are represented in the form of crystal lattice blocks (Fig. 1, d). Cracks (Fig. 1, e) and cracks with metal contamination (Fig. 1, f) can be located both on the crystal surface and inside diamond, having the extent from some nanometers to a few micrometers. The defects under the total influence of high temperature and increased cutting force interact with grinding surface on an atomic level. Example, diffusion of carbon out of the machining surface to the diamond crystal can be observed at temperature above $700^{\circ} \mathrm{C}$, but diffusion of carbon out of the diamond crystal to the machining surface can be observed at temperature above $800^{\circ} \mathrm{C}$.

The greater amont of metal contamination the higher oxidation rate of diamond crystals. Under electrical diamond grinding they can interact with electrolyte, and thus dicrease cutting properties of wheel grit. 
So far as point defects can originate threedimensional ones, there are both platelets (Fig. 1, g) and planar (Fig. 1, h, i) defects in the crystal. Threedimensional defects as well as point ones can be located on the crystal surface and inside diamond grains, therefore diamond crystal fracture directly depends upon an external cutting force and heat process.
Platelets defects (Fig. 1, g) are formed out of carbon interstitial atoms with nitrogen impurity [19, 22].

Nano-sized voidites can be of length from one nanometer (Fig. 1, h) to a few micrometers (Fig. 1, i) and located between grains of a similar orientation at their boundaries or along dislocation lines [19, 22].

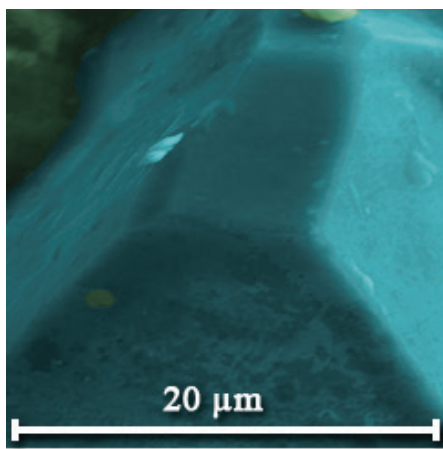

a)

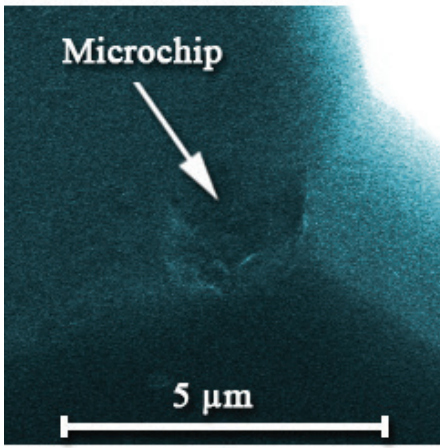

d)

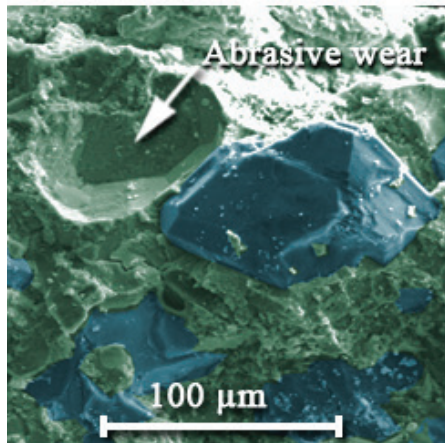

g)

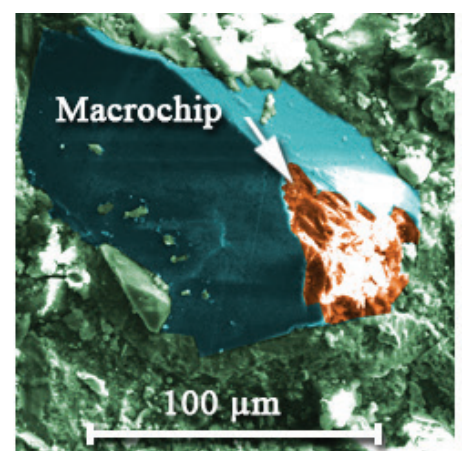

b)

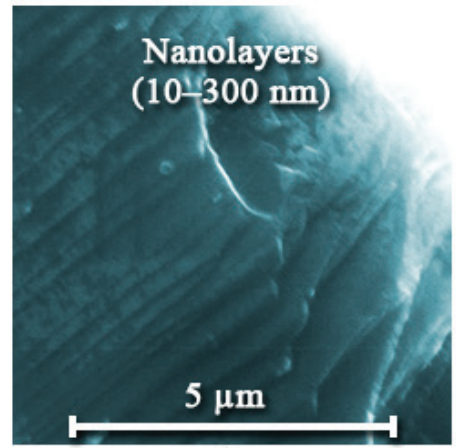

e)

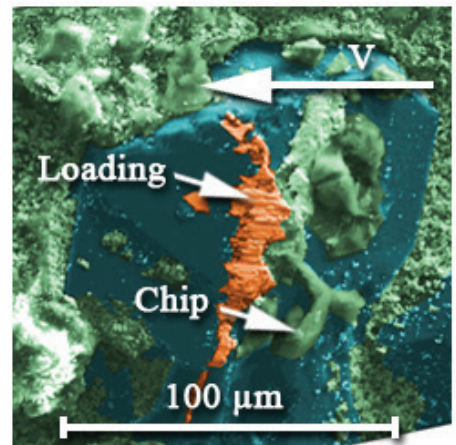

h)

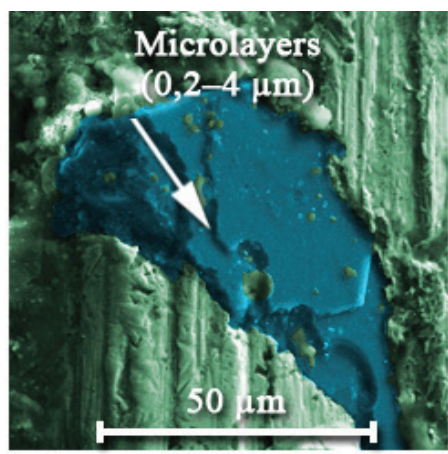

c)

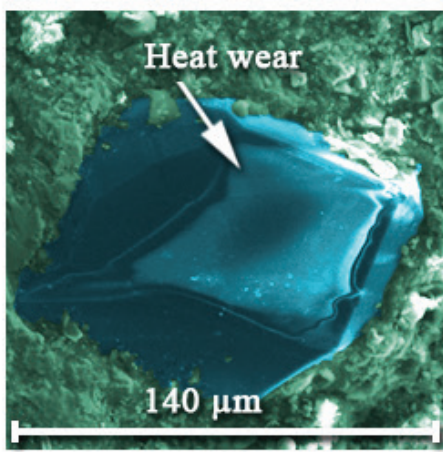

f)

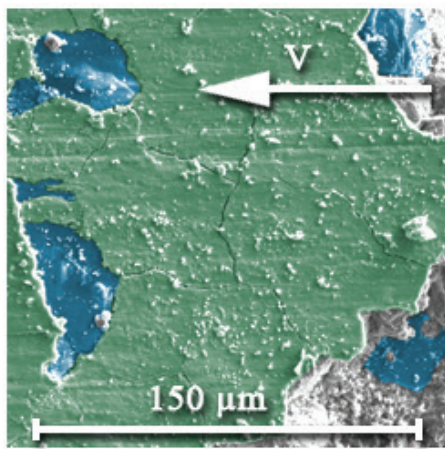

i)

Fig. 2. Typical diamond wear (crystal face failure) under grinding: a) cutting diamond face before grinding; b) three-demencional failure (volume fracture) of the diamond top in form of macrochip; c) cutting face wear along microlayer growth; d) threedemencional failure (volume fracture) of the diamond top in form of microchip; e) cutting face wear along nanolayer growth; $f$ ) fretting of cutting face resulting in formation of a smooth wear surface; g) diamong breakoff out of wheel bond; h) loading of the cutting face; i) totally loaded diamonds.

\section{Effect of point and three-dimensional defects on diamond wear}

In grinding the most crystals (grit) of the grinding wheel will save their shape and integrity. (Fig. 2, a). However, it would suggest some point defects and threedemensional ones, presenting in crystals, caused their definite wear out. The three-demensional rapture of the diamond's top occurs in form of macrochip (Fig. 2, b) or microchip (Fig. 2, d) along tiny (micro) cracks on the surface of crystal. It should be noted that a diamond crystal consists of nanolayers, so to say growth stages, which have the size of from 10 to $300 \mathrm{~nm}$ (Fig. 2, e). These nanolayers are subsequently formed into microlayers having the dimension form 0,2 to $4 \mu \mathrm{m}$ (Fig. 2, c). It is remarkable that such a devision of wear to micro and macro levels might be observed at rupture of diamond cutting surfaces, which are in direct contact with a machining surface. 
It is reckoned [1, 3-12, 17, 18, 23], that depending on the machining mode and physico-chemical properties of the work surface, diamond wear process pattern can be devided into: abrasive (Fig. 2, g), adhesion (Fig. 2, h), diffusion and heat wears (Fig. 2, f). But the comprehensive study of the wheel surface has revealed $[19,21,24]$ that, with no dependence on the machining condition, crystals of all types of wear can be observed on the level above the wheel bond (Fig. 2, i). Obviously, it is because defects give rise to nonuniform stress in a crystal. Deformation occurs during grinding and initiates converging of point defects (C-defects), but grinded-off chips, being ingressed into cracks, expand them and provoke one or another type of wear.

Hence, it is clear that the most diamond defects come from availability of only one foreign atom $(\mathrm{N}, \mathrm{H}, \mathrm{O}, \mathrm{Ni}$, $\mathrm{Cr}, \mathrm{Co}$, etc.), or lack of one carbon atom in a crystal lattice. Surely the defects can develope further under high temperature and pressure in the cutting zone [2428]. It seems plausible that synthesis of defect-free diamonds might be one of the promising ways to prevent loading of metal-bonded grinding wheels [21, 29-31].

However, while further work is under way, by now there is a possibility to reduce a loading impact significantly by the following steps:

- create a preventive film on the wheel surface;

- replace standard electrolyte with alternative lubricoolant;

- develope and implement new advanced designs of grinding wheels;

- active wheel dressing during grinding in accordance with the technology of electro-diamond machining;

- combination of above-mentioned methods.

\section{Conclusions}

The presence of different defects in diamonds has a strong influence on their physical properties and abrasive tool performance, that in turn, has a bad effect on the workpiece quality.

After synthesis cracks occuring on a crystal face or inside crystal as well as cracks filled up with metal inclusion give rise to adhesion-diffusion loading of the abrasion layer with workpiece chips.

Up-to-date additive technology provide designers with new technological solutions and oppotunities at modelling of materials by molecular dynamics method.

The reported study was funded by RFBR according to the research project No. 16-38-00123 мол_а.

\section{References}

1. W.B. Rowe, 2nd ed. Oxford: Elsevier, (2014)

2. J. Badger, S. Murphy, G.E. O'Donnell, AMR, 126128 (2010) 597-602

3. S. Malkin, Guo Changsheng, New York, Industrial Press, (2007)

4. M.J. Jackson, J.P. Davim, Springer US, (2011)
5. I.D. Marinescu, M.P. Hitchiner, E. Uhlmann, W.B. Rowe, I. Inasaki, CRC Press, (2016)

6. R.I. King, R.S. Hahn, Springer Science \& Business Media, (2012)

7. H.G. Sachsel, C.A.E. Precision, Xlibris Corporation, (2010)

8. M. Schöpf, I. Beltrami, M. Boccadoro, D. Kramer, CIRP AMT, 50 (1), 125-128 (2001)

9. E. Brinksmeier, Y. Mutlugunes, F. Klocke, J.C. Aurich, P. Shore, H. Ohmori, CIRP AMT, 59 (2), 652-671 (2010)

10. A.G. Mamalis, M. Horvath, A.I. Grabchenko, J. MPT, 97 (1-3), 120-125 (2000)

11. J.B.J.W. Hegeman, J.Th.M. De Hosson, G. De With, Wear, 248 (1-2), 187-196 (2001)

12. C.C. Chang, A.Z. Szeri, Wear, 216 (1), 77-86 (1998)

13. B. Zhang, X.L. Zheng, H. Tokura, M. Yoshikawa, J. MPT, 132 (1-3), 353-364 (2003)

14. H. Hamdi, H. Zahouani, J.M. Bergheau, J. MPT, 147 (3), 277-285(2004)

15. P. Durgumahanti, V. Singh, R.P. Venkateswara, Inter. J. MTM, 50 (3), 231-240 (2010)

16. Z. Zhang, F. Huo, Y. Wu, H. Huang, Inter. J. MTM, 51 (1), 18-24 (2011)

17. X. Chen, W.B. Rowe, R. Cai, Inter. J. MTM, 42 (5), 585-593 (2002)

18. J. Webster, M. Tricard, CIRP AMT, 53 (2), 597-617 (2004)

19. V.Y. Popov, A.S. Yanyushkin, A.N. Khlystov, Metal Working and Material Science, 4, 16-23 (2016)

20. V.Y. Popov, A.N. Khlystov, A.V. Bondin, CRM, 8 (1) 161-172, (2016)

21. V.Yu. Popov, A.S. Yanyushkin, Y.I. Zamashchikov, AMM, 799-800, 291-298 (2015)

22. J.H. Chen, D. Bernaerts, J.W. Seo, G. van Tendeloo, H. Kagi, Mag. Let., 77 (3), 135-140 (1998)

23. L.A. Bokhoeva, V.E. Rogov, A.S. Chermoshentseva, D.V. Lobanov, IOP Conf. Ser.: MSE, 142, 012077 (2016)

24. V. Ivancivsky, K. Parts, V. Popov, AMM, 788, 129135 (2015)

25. V.Yu. Skeeba, V.V. Ivancivsky, N.V. Martyushev, D.V. Lobanov, N.V. Vakhrushev, A.K. Zhigulev, KEM, 712, 105-111 (2016)

26. V.Yu. Skeeba, V.V. Ivancivsky, A.V. Kutyshkin, K.A. Parts, IOP Conf. Ser.: MSE, 126, 012016 (2016)

27. Hossam Halfa, J. MMCE, 1, 257-270 (2013)

28. D.V. Lobanov, P.V. Arkhipov, A.S. Yanyushkin, V.Yu. Skeeba, IOP Conf. Ser.: MSE, 142, 012081(2016)

29. V.Yu. Skeeba, V.V. Ivancivsky, D.V. Lobanov, A.K. Zhigulev and P.Yu. Skeeba, IOP Conf. Ser.: MSE, 125, 012031(2016) 
30. V.V. Ivancivsky, V.Yu. Skeeba, I.A. Bataev, D.V. Lobanov, N.V. Martyushev, O.V. Sakha, I.V. Khlebova, IOP Conf. Ser.: MSE, 156, 012025 (2016)

31. A.S. Yanyushkin, D.A. Rychkov, D.V. Lobanov, Procedia Engineering 150, 942-947 (2016) 